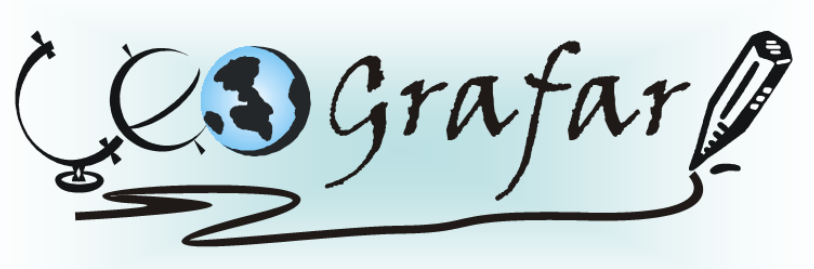

Revista Eletrônica do Programa de Pós-Graduação em Geografia - UFPR

\title{
ESPAÇO E TRIBALISMO: UMA DISCUSSÃO A PARTIR DO UNIVERSO ESCOLAR
}

\author{
DANIEL LUIZ STEFENON ${ }^{1}$
}

\begin{abstract}
RESUMO
De acordo com Maffesoli, vivemos um tempo marcado pela tribalização das relações sociais. Ao criticar a consideração de que a sociedade ocidentalizada caminha para uma individualização, este autor mostra que cada vez mais, a constituição de grupos afetuais, cimentados pela partilha de uma estética comum, caracteriza nossa sociedade. A escola é uma expressão desse processo. O convívio dos grupos/tribos no interior da escola provoca uma ressignificação de seu espaço, sendo que o cotidiano vivido dentro e próximo da escola torna-se o monumento que ressemantiza o espaço escolar, podendo ser visto agora enquanto um espaço de representação. O espaço de representação, a partir de uma abordagem que o considera uma síntese entre os mundos material, social e simbólico, revela-se como uma ferramenta de compreensão do mundo consensual, banal. É nesta esfera que a vida acontece e torna-se inteligível. Esta "potência subterrânea" que é a socialidade contemporânea, utilizando-se das palavras de Maffesoli, que resiste às grandes ideologias coletivas que homogeneizam a vida social, emerge, justamente, no espaço de representação. Ele é o espaço das possibilidades das relações sociais, o local onde as direções são estabelecidas e onde, em comum, o mundo passa a ser sentido. A escola, dessa forma, adquire significados que são produtos das relações sociais processadas num contexto de tribalização das interações, tornando-se expressão da cultura desses novos tempo e espaço.
\end{abstract}

Palavras-chave: Geografia, escola, tribalização, espaço de representação.

\footnotetext{
${ }^{1}$ Mestre pela UFPR e Professor da área de Ensino de Geografia do Departamento de Geografia da Universidade Estadual do Centro-Oeste (UNICENTRO), campus de Irati - PR; E-mail: dstefenon@bol.com.br.
} 


\title{
SPACE UND TRIBALISM: A DISCUSSON FROM THE SCHOLAR UNIVERSE
}

\begin{abstract}
According Maffesoli, we live in a time marked by tribalization of social relations. In your critical about the view that westernized society is based in individualism, the author shows that increasingly, the formation of affective groups, joined by sharing a common aesthetic, characterizes our society. The school is an expression of that process. The coexistence of the groups/tribes in the school leads to a redefinition of their space, and the daily lived in and near the school becomes in the monument that resignify the school environment, and can now be seen as a space of representation. The space of representation, a synthesis between the material, social and symbolic worlds, is a tool for understanding the consensual world. It is this sphere that life happens and it becomes intelligible. This "underground power" that is contemporary sociality, using the words of Maffesoli, which resists the grand ideologies that homogenize the collective social life, emerges precisely in the space of representation. It is the space of possibilities of social relations, where the directions are established and where, in common, the world becomes experienced. The school acquires meanings that are products of social relations processed in the context of tribalization of the interactions, and becomes an expression of the culture of these new time and space.
\end{abstract}

Key words: Geography, school, tribalization, space of representation.

\section{INTRODUÇÃO}

A Geografia, tradicionalmente, tem se ocupado em produzir discursos acerca de espaços que, aparentemente, apresentam existência efetiva no mundo conhecido como "real". Contudo, com a emergência de temáticas ligadas ao imaginário, novas possibilidades surgem ao geógrafo, e elas estão relacionadas com o que MerleauPonty (2006) chamou de segundo espaço, ou seja, de uma dimensão espacial que é exclusivamente produto da consciência humana e dos sentidos que o homem atribui aos lugares pelos quais estabelece seu itinerário cotidiano.

O trabalho de pesquisa realizado em uma escola pública da periferia de Curitiba (STEFENON, 2009) ${ }^{2}$ evidencia esse movimento de ressemantização que os grupos impõem aos espaços, processo que, em sua origem, apresenta marcantes componentes sociais.

Este artigo busca retomar algumas das reflexões desenvolvidas durante a referida pesquisa mediante a discussão de aspectos que nesse momento nos

\footnotetext{
${ }^{2}$ Dissertação de Mestrado orientada pelo Prof. Dr. Sylvio Fausto Gil Filho.
} 
parecem caros: a tribalização das relações sociais, sob o prisma da teoria de Michel Maffesoli; e o processo de produção de espaços simbólicos por essas tribos, a partir de apontamentos acerca do universo escolar e do conceito de espaço de representação. A escola, dentro dessa perspectiva, - e sem deixar de se distanciar de sua materialidade -, apresenta-se enquanto um mundo de significados, construídos a partir da construção de redes de socialização que emprestam do processo de tribalização das relações sociais sua própria forma.

\section{CARACTERÍSTICAS DO TRIBALISMO}

Universidade, imprensa, política, sindicato, poder-se-ia continuar a lista: administração, clubes, formação, assistência social, patronato, igrejas etc. $O$ processo tribal tem contaminado o conjunto das instituições sociais. E é em função dos gostos sexuais, das solidariedades de escolas, das relações de amizade, das preferências filosóficas ou religiosas que vão se constituir as redes de influência, a camaradagem e outras formas de ajuda mútua, das quais se tratou, que constituem o tecido social. (MAFFESOLI, 2006, p. 1314).

A tese de Michel Maffesoli busca desmistificar a consideração de que, no decorrer de sua autoconstrução, a sociedade "ocidentalizada", urbana, "pósmoderna", vem se atomizando, estabelecendo um modelo de vivência baseada no individualismo. O universo das idéias compartilhadas, vividas no cotidiano das comunidades e instituições, está hoje permeado, mais do que nunca, pela efervescência de um "estar junto" extremamente peculiar, carregado de sentidos e formas que são expressões claras de nosso tempo: o tempo das tribos.

As idéias de Maffesoli apoiam-se em um paradoxo essencial que the chama a atenção e motiva seu pensamento, que em suas palavras é "o vaivém constante que se estabelece entre a massificação crescente e o desenvolvimento dos microgrupos (...)". (MAFFESOLI, 2006, p. 31). A peculiaridade histórica dessa relação atualmente aponta para a constituição de um tempo, uma era, onde a "socialidade" se sobrepõe ao "social". De acordo com o autor, enquanto o social, atributo da sociedade "moderna", tem uma estrutura mecânica de funcionamento e se apóia na função que os indivíduos exercem dentro de grupos contratuais conectados à organizações econômicas e políticas, a socialidade é uma estrutura complexa, orgânica. Nesta, as pessoas desempenham papéis derivados de suas escolhas, gostos, desejos, e se inserem em grupos sociais, que segundo ele, adquirem uma feição de "tribos 
afetuais". Tais tribos contém um sentido de reunião que não tem um fim preciso, e está ligado apenas à vontade de "estar junto" e compartilhar uma mesma forma de experimentar o mundo, desvinculado, em suma, de qualquer grande ideologia unificadora.

A "estética" desempenha um papel capital na constituição e manutenção dos grupos. De acordo com o autor, é preciso entender o termo "estética" a partir de seu sentido mais profundo, que segundo ele tem a ver com a faculdade comum de sentir e experimentar o mundo. Partindo disso, indica que os microgrupos contemporâneos têm na estética o elemento que os cimenta e dá sentido à sua existência. Essa estética, a propriedade de sentir em comum, portanto, surge da partilha, no grupo, de sentimentos e emoções, que muito mais do que a própria razão, são os elementos que possibilitam a difusão das representações acerca do mundo, que vão caracterizar a identidade do grupo.

Ao falar de um "estar junto à toa" (MAFFESOLI, 2006, p. 137), o autor expõe sua tese sobre o fato de que esta "socialidade" que emerge do emaranhado das relações que se processam no interior de nossa sociedade, é uma "forma pura" de socialização. Ela é caracterizada por uma maneira "lúdica" de desenvolver os laços grupais, que é composta por ações que não incluem uma necessidade evidente de se ter uma finalidade, uma utilidade ou uma aplicação prática das/nas atividades do grupo.

A partilha de emoções no interior do grupo, agindo de maneira a promover sua coesão, sua permanência, empresta ao tribalismo contemporâneo aspectos que o aproximam de modelos religiosos de socialização. Já desde Durkheim (1970, 1996), que os elementos da religião e o próprio ritual religioso são considerados como importantes e essenciais fatores de atração social. De acordo com Maffesoli (2006), no caso dos microgrupos tribais de nosso tempo, emoção e ritual se confundem. O culto, seja à uma determinada estética, seja à algum herói "pop", desempenha um papel de reforçador da identidade e da coesão do grupo, contribuindo para a constituição das idéias compartilhadas entre seus membros. O autor relaciona o fenômeno das tribos com os vários grupos de primeiros cristãos, que de maneira análoga tinham como características fundamentais a opção pela inscrição local e pela informalidade da organização social. Tais características 
atribuíam/atribuem às idéias e emoções compartilhadas um poder central na constituição de ambos.

Esta nova socialidade busca estabelecer-se a partir de um contexto onde as escolhas tornam-se o elemento sobressaliente da constituição social do indivíduo. $O$ grupo é o universo absoluto de si mesmo e somente sua "estética", no sentido "maffesoliano" do termo, justifica as escolhas feitas por aqueles que compartilham sua vivência, em detrimento, portanto, das grandes ideologias políticas orientadoras das práticas sociais.

Uma outra e também muito importante característica do tribalismo contemporâneo, é a "lei do segredo". O autor tenta demonstrar que

a máfia podia ser considerada como a metáfora da socialidade. (...) Em particular, insistindo, por um lado, no mecanismo de proteção em face do exterior, isto é, em face das formas superimpostas de poder, e ressaltando, por outro lado, como o segredo, dessa maneira, era um modo de fortalecer o grupo (MAFFESOLI, 2006, p. 155).

Admitindo essa dupla função do segredo, que é de se proteger das ameaças do exterior e de fortalecer a coesão do grupo, podemos afirmar que um jogo dialético se impõe nessa relação, que tem a ver com a necessidade do grupo de saber dosar prudentemente aquilo que é pra ser mostrado e aquilo que é pra ser escondido. Nesse ponto, podemos falar da instauração de um tipo de sociedade secreta. Dessa maneira, a partilha do sentimento do grupo exige o investimento de um tipo de máscara que, evidentemente, contribui para a inclusão do indivíduo no grupo, "desindividualizando-o", fazendo-o pertencer ao clã, à tribo. Isso nos faz pensar sobre mais uma diferença fundamental entre o formato "social" e o de "socialidade" que predomina no tempo das tribos. Enquanto o social tende à centralização, especialização, universalização, a sociedade secreta está à margem, é descentralizada, restrita àqueles que compartilham do ritual estético do grupo.

Além disso, a lei do segredo, dentre outras, exerce uma função muito clara:

O fato de partilhar um hábito, uma ideologia, um ideal determina o estarjunto, e permite que este seja uma proteção contra a imposição, venha ela do lado que vier. (...) A confiança que se estabelece entre os membros do grupo se exprime por meios de rituais, de signos de reconhecimento específicos, que não tem outro fim senão o de fortalecer o pequeno grupo contra o grande grupo. (...) A partilha secreta do afeto, ao mesmo tempo em 
que confirma os laços próximos, permite resistir às tentativas de uniformização (MAFFESOLI, 2006, p. 159).

A sociedade secreta da tribo, dessa forma, se mostra disposta a estabelecer um círculo de proteção ao ideal estético produzido na grande coletividade da sociedade, funcionando como uma família estendida, que naturalmente preserva tais ideais frente às imposições do exterior.

Por fim, é a constituição em rede dos microgrupos contemporâneos que oferece à capacidade criativa das massas sua expressão mais acabada. Essa criação pura, sem finalidade, esse modo puro de viver vem impregnando os modos de vida atualmente. A correlação entre esses peculiares estilos de vida e a grande massa, edifica-se exatamente sobre o fato de que um grupo só é compreensível no interior de um conjunto. $O$ objetivo principal deles é se manterem aquecidos e principalmente "repercurtir", ganhar visibilidade no conjunto social. Essa é a rede, os "plug-ins" que ligam o grupo à massa.

O que a modernidade ou a ordem do político uniu, homogeneizou, a ordem tribal implodiu. Presenciamos um retorno à diferença, pois esta é o que cimenta o conjunto. A nova cultura é plural, contraditória. Acima da efervescência e do turbilhonamento causados pela diversidade alucinante dos grupos, emerge esta realidade que se faz própria a partir da convivência da pluralidade.

Adjacente aos processos de distinção do grupo frente ao conjunto da massa, o espaço assume, cada vez mais, um papel central. Maffesoli (2006, p. 11), diz que "o tribalismo lembra, empiricamente, a importância do sentimento de pertencimento, a um lugar, a um grupo, como fundamento essencial de toda vida social." O espaço, o lugar, adquire contornos determinantes nesse processo. É na proximidade, no encontro das pessoas, que a coletividade dos grupos é construída, e é na convivência em determinados locais que o grupo encontra abrigo e se mantém, autoreproduzindo-se.

\section{A ESCOLA ENQUANTO ESPAÇO DE REPRESENTAÇÃO}

A tese de Maffesoli, acerca do tribalismo nas relações sociais na contemporaneidade, traz profundas contribuições acerca da questão do espaço. 
Este novo tipo de socialidade, como o autor se refere, nos induz a compreender a identidade de cada um como sendo a identidade de sua própria comunidade que, por conseguinte, encontra na sua espacialidade as bases de sua própria existência e reprodução. Ele nos chama atenção à um elemento bastante importante do tribalismo, ao qual denomina "proxemia", termo que deriva do latim proximu, que também dá origem às palavras "próximo" ou "proximidade".

Há momentos em que o indivíduo significa menos do que a comunidade na qual ele se inscreve. Da mesma forma, importa menos a grande história factual do que as histórias vividas no dia-a-dia, as situações imperceptíveis que, justamente, constituem a trama comunitária. Esses são os dois aspectos que me parecem caracterizar o significado do termo "proxemia" (MAFFESOLI, 2006, p. 198).

Dessa forma, parece-nos que neste ponto o autor torna bastante clara a sua concepção do ser humano dos tempos do tribalismo contemporâneo: o homem relacional. Não somente em relação com os outros, mas também com o seu território-comunidade, que vai de certa maneira funcionar como moldura e fundo do complexo processo de produção das representações do grupo acerca do mundo.

De acordo com a pesquisa realizada, o processo de tribalização das relações sociais, no âmbito da escola, produz uma ressignificação de seu espaço. O convívio no espaço escolar de identidades tribais plurais (punks, emos, hiphopers, roqueiros, dentre outras), faz com que a escola deixe de se constituir apenas enquanto objeto material e instituição, e passe a significar um locus da partilha e do enfrentamento de perspectivas. A escola, em sua "segunda dimensão", torna-se um espaço de representação, produto dos significados atribuídos por seus freqüentadores.

O termo "espaço de representação", por conseguinte, foi proposto inicialmente pelo historiador alemão Georg Mosse, que realizou um estudo acerca dos espaços e dos monumentos criados pela Alemanha Nazista que tinham a nítida intenção de promover a cristalização da idéia de pátria. É à esse espaço "sacralizado" e tornado monumento pelo mundo da política que Mosse então atribui a denominação de "espaço de representação". (BETTANINI, 1982).

Um espaço de representação se constrói com a intenção de se legitimar uma determinada ordem institucional. Com a derrocada das estruturas de uma dada organização social, novas estruturas organizacionais ganham corpo, o que potencializa a necessidade da representação no espaço dos ideais norteadores 
dessa nova ordem, promovendo-se assim a "monumentalização" dos espaços. Eis a "necessidade de construir espaços de representação que ilustrem a cronologia revolucionária e derrubem ou transformem os espaços da organização passada" (BETTANINI, 1982, p. 99).

Dessa forma, o espaço de representação torna-se um produto da construção coletiva, e revela-se como um elemento central no processo de afirmação e legitimação da organização social que o constitui. No entanto, este espaço de representação, enquanto locus da manifestação de ideais coletivos, pode extrapolar essa dimensão pura da política. De acordo com Bettanini (1982, p. 107), "é talvez o momento de abandonar os monumentos do espaço de representação e de se aproximar dos documentos do espaço quotidiano, transformando-o em monumento", e dessa forma constituir um discurso que apontaria para uma melhor compreensão das comunidades habitantes desses espaços.

Essa outra dimensão dessa modalidade espacial se expressa no mundo cotidiano das idéias consensuais. Neste ponto, encontramos uma possível aproximação do conceito com as contribuições de Serge Moscovici e de sua teoria acerca das representações sociais, entendidas aqui enquanto sistemas de concepções, valores e idéias que existem independentemente da experiência puramente individual. (MOSCOVICI, 2003). Ao propor a ideia de que a as representações sociais são produtos de um universo consensual - relativo ao mundo do senso comum - em oposição a um universo reificado - referente ao mundo formal, institucionalizado -, o autor nos fornece elementos que contribuem significativamente com o processo de compreensão da dinâmica dos espaços de representação. Dentro dessa perspectiva, ele torna-se "o reino da esfera consensual' (GIL FILHO, 2003, p. 13), o mundo-síntese entre a materialidade do real, a socialidade dos grupos, e os significados atribuídos por eles; é um espaço simbólico - um segundo espaço - onde são possíveis as relações e a conseqüente construção e partilha das representações dentro dos microgrupos tribais contemporâneos. Ou ainda,

o espaço de representação é um espaço vivo, locus da ação e das situações vivenciadas. É relacional em percepção, diferencialmente qualitativo e dinâmico e de natureza simbólica. Deste modo, revela-se como categoria relevante na construção de uma geografia do mundo cultural além da leitura economicista reinante da análise espacial. (GIL FILHO, 2003, p. 13). 
Negligenciar o papel da espacialidade na constituição e manutenção dos grupos é desconsiderar o papel que as relações desempenham dentro deles. $\mathrm{O}$ espaço de representação, a partir de uma abordagem que o considera uma síntese entre os mundos material, social e simbólico, revela-se como uma ferramenta de compreensão do mundo consensual, banal. É nesta esfera que a vida acontece e torna-se inteligível. Esta "potência subterrânea" que é a socialidade contemporânea, utilizando-se das palavras de Maffesoli, que resiste às grandes ideologias coletivas que homogeneizam a vida social, emerge, justamente, no espaço de representação. Ele é o espaço das possibilidades das relações sociais, o local onde as direções são estabelecidas e onde, em comum, o mundo passa a ser sentido.

\title{
4 ESCOLA, TRIBO E ESPAÇO: CONSIDERAÇÕES FINAIS
}

Como afirma Enguita (apud SACRISTÁN e GÓMEZ, p. 19),

\begin{abstract}
a escola é um cenário permanente de conflitos. O que acontece na aula é o resultado de um processo de negociação informal que se situa em algum lugar intermediário entre o que o professor/a ou a instituição escolar querem que os alunos/as façam e o que estes estão dispostos a fazer.
\end{abstract}

Tanto nesse campo da prática, como no das idéias, ou das representações, a escola, por excelência, é um ambiente de convívio e enfrentamento entre um universo consensual e um reificado. Pelo fato de possuir, dentre outras, a função de transmissão do conhecimento científico, e por se constituir em um ambiente notavelmente institucionalizado, impõe aos atores construtores de sua realidade determinados papéis que induzem respectivos comportamentos e atitudes. Esse universo de ideias reificadas projeta-se sobre o mundo das representações geradas no cotidiano, que em sua essência, tem na lógica das tribos afetuais, o seu motivo gerador.

O sentido atual do "estar junto", imposto pelas tribos, se distancia das grandes ideologias motivadoras da modernidade, e revela uma nova perspectiva ao processo de socialização, a qual Maffesoli chamou de "pura". A socialização é "pura" porque o simples fato de se estar reunido encerra em si a motivação para tal. É o que o autor 
chama de "estar junto à toa". O processo de tribalização na perspectiva maffesoliana, juntamente com os ideais estéticos que carrega consigo, tem um poder muito grande sobre a produção e (re)produção das representações sociais no interior da escola. Compartilhar das representações que são comuns aos pares, torna-se uma condição imprescindível ao pertencimento no grupo.

A escola, por excelência, é um campo de convívio tribal. Nela as tribos encontram o ambiente propício para alcançar a almejada visibilidade social. A questão da tribo, encerra em si uma outra, que é a da identidade. Fazer com que determinadas identidades repercutam no ambiente amplo da rede social que se desenvolve na escola é um trabalho de profunda negociação simbólica, através do qual, seja por meio de um determinado comportamento ou de uma maneira específica de se vestir ou falar, os indivíduos buscam projetar-se sobre os outros. De certa forma, essas considerações nos conduzem a visualizar a escola e sua rede de relações sociais como um grande grupo que carrega consigo elementos de tribalização.

Na escola, "tudo é separado, você pode ver. Os vileiros, basquetes, boleiros. É só sair para o recreio e ver. Aí você escolhe o que você curte, o que você gosta"3. A escola, de certa forma, torna-se uma "prateleira" de identidades, onde os indivíduos que a frequentam tendem a inserir-se nos grupos que se inscrevem em seu espaço, criando assim um complexo jogo de interação e de socialização entre eles. Fazer parte de um grupo é submeter-se às suas "regras" e esforçar-se para adquirir seus traços característicos, que são constituídos por aspectos que vão desde a forma de se vestir, falar, até padrões de comportamento específicos compartilhados por seus membros.

A partir das metodologias de entrevistas semi-estruturadas e de reuniões em grupos focais, pudemos constatar que muitas tribos convivem dentro do ambiente da escola. Dentre elas, conforme o depoimento dos próprios alunos, podemos citar algumas, como "hip hop", "roqueiros", "emos", "pagodeiros", torcidas organizadas, pessoas com afinidade à algum tipo de esporte (como o voleibol, basquetebol, futebol, etc.), "skatistas", "otakus" (apreciadores de mangás e animes, que são histórias em quadrinhos e desenhos animados em estilo japonês), "gamers"

\footnotetext{
${ }^{3}$ Depoimento dado por um aluno do Colégio Estadual Segismundo Falarz em outubro de 2008.
} 
(praticantes de jogos eletrônicos), praticantes de "le parcour", escoteiros, "regueiros", góticos, "patricinhas e mauricinhos", "nerds", dentre outras.

A escola entendida como um ambiente de partilha e convergência de identidades culturais distintas e complementares torna-se um grande grupo, uma grande tribo, onde os indivíduos, à sua maneira, buscam incluir-se, projetando sua imagem perante os outros. Ou seja, integrar um microgrupo tribal é também incluirse no amplo contexto da coletividade.

Ao buscar a participação no contexto do grande grupo projetando-se sobre ele, a tribo impõe novos contornos ao espaço que fundamenta e dá sustentação a essas relações. Esse, agora ressemantizado, espaço de representação, torna-se real no mundo simbólico da imaginação, sendo possível sua inteligibilidade a partir de uma geografia essencialmente humana, ou seja, preocupada com o mundo de significados que criamos para conformar o real, o que é característica e exclusividade da cultura humana.

\section{REFERÊNCIAS}

BETTANINI, Tonino. Espaço e ciência humanas. Rio de Janeiro: Paz e Terra, 1982.

DURKHEIM, Émile. As formas elementares da vida religiosa: o sistema totêmico na Austrália. São Paulo: Martins Fontes, 1996.

Representações Individuais e Representações Coletivas. In: Sociologia e Filosofia. Rio de Janeiro: Forense Universitária, 1970.

GIL FILHO, Sylvio Fausto. Espaço de Representação: Uma Categoria Chave para a análise cultural em Geografia. In: Anais do I Encontro Sul-Brasileiro de Geografia. Curitiba: AGB, 2003.

Geografia Cultural: estrutura e primado das representações. Espaço e Cultura, Rio de Janeiro, no. 19-20, p. 51 à 59, janeiro/dezembro de 2005.

MAFFESOLI, Michel. O tempo das tribos: o declínio do individualismo nas sociedades pós-modernas. Rio de Janeiro: Forense Universitária, 2006.

MERLEAU-PONTY, Maurice. Fenomenologia da percepção. São Paulo: Martins Fontes, 2006. 
MOSCOVICI, Serge. Representações Sociais: investigações em psicologia social. Petrópolis: Vozes, 2003.

Prefácio. In: GUARESCHI, Pedrinho; JOVCHELOVITCH, Sandra. Textos em representações sociais. Petrópolis: Vozes, 1995.

SACRISTÁN, José Gimeno e GÓMEZ, Ángel Ignacio Pérez. Compreender e Transformar o Ensino. Porto Alegre, Armed, 2000.

STEFENON, Daniel Luiz. O espaço de representação dos grupos sociais na escola: o caso do Colégio Estadual Segismundo Falarz, Bairro Hauer, Curitiba-PR. Dissertação de mestrado. Curitiba: UFPR, 2009.

(Recebido em 08.03.2011. Aceito em 02.09.2011) 